\title{
Three new species of Oxyethira Eaton, 1873 (Trichoptera: Hydroptilidae) from New Caledonia
}

\author{
Bruna Maria Silva CAVALCANTE ${ }^{1, *} \&$ Kjell Arne JOHANSON ${ }^{2}$ \\ ${ }^{1}$ Laboratório de Entomologia, Departamento de Zoologia, Instituto de Biologia, Universidade Federal \\ do Rio de Janeiro, Caixa Postal 68044, 21941-971, Rio de Janeiro, RJ, Brazil. \\ ${ }^{1}$ Programa de Pós-graduação em Zoologia, Museu Nacional, Universidade Federal do Rio de Janeiro, \\ RJ, Brazil. \\ ${ }^{2}$ Zoology Department, Swedish Museum of Natural History, Box 50007, SE-104 05 Stockholm, \\ Sweden.
}

"Corresponding author: bmsilva.bio@gmail.com

2Email: kjell.arne.johanson@nrm.se

${ }^{1}$ urn:1sid:zoobank.org:author:7C9D157E-B681-4372-88DB-F79EE3A551EB

${ }^{2}$ urn:lsid:zoobank.org:author:F2A38CF6-59EB-4F88-BFEB-761DBEA7B01A

\begin{abstract}
Oxyethira Eaton, 1873 is one of the most diverse genera of Hydroptilidae, comprising over 240 species distributed in all biogeographical regions. Here three new species of Oxyethira (Trichoglene) Neboiss, 1977 are described and illustrated from male specimens collected in New Caledonia: $O$. (Trichoglene) hamus sp. nov., recognized by the hook-shaped apex of the long inferior appendages in lateral view and by the posterior margin of segment IX with a trilobed appearance in ventral view; $O$. (Trichoglene) rectangulata sp. nov., recognized by the rectangular shape of the inferior appendages, which are totally fused and with two pairs of small setae on the inner face; and $O$. (Trichoglene) spiralis sp. nov., recognized by the strongly curvilinear shape of the subgenital process in dorsal and lateral views and by the long process spiralling around the ejaculatory duct at the phallus apex.
\end{abstract}

Key words. Hydroptilidae, New Caledonia, microcaddisflies, Oxyethira, taxonomy.

Cavalcante B.M.S. \& Johanson K.A. 2022. Three new species of Oxyethira Eaton, 1873 (Trichoptera: Hydroptilidae) from New Caledonia. European Journal of Taxonomy 789: 1-10. https://doi.org/10.5852/ejt.2022.789.1623

\section{Introduction}

The microcaddisfly genus Oxyethira Eaton, 1873 (Trichoptera: Hydroptilidae: Hydroptilinae) includes 247 extant and one fossil species (Morse et al. 2021). It has been recorded from all zoogeographic regions, and is especially diverse in the New World, with more than 100 species registered (Holzenthal \& Calor 2017). Oxyethira species are currently grouped into 11 subgenera, but 29 species remain as incertae sedis (Kelley 1984, 1989; Oezdikmen 2007; Morse et al. 2021). The subgenus Trichoglene Neboiss, 1977 (26 species) has an Australasian distribution and occurs in Australia, New Caledonia and New Zealand (Wells \& Johanson 2015; Morse et al. 2021). 
A total of 26 species of Oxyethira are registered from New Caledonia belonging to 3 subgenera: Dampfitrichia Mosely, 1937 (one species), Pacificotrichia Kelley, 1989 (13 species) and Trichoglene Neboiss, 1977 (11 species). Another species, O. macropennis Wells \& Johanson, 2015, remains unplaced to subgenus (Wells \& Johanson 2015; Johanson \& Wells 2019).

The diagnostic characteristics for the males in the subgenus Trichoglene are as follows: segment VIII without excision (considered as a plesiomorphic feature); short titillator (even absent in some species); phallus with a curved spine-shaped process in the sub-distal region; and subgenital processes widely separated and partially fused with the pleural region of segment IX (the two latter are considered apomorphic features) (Kelley 1984).

Three species groups are recognized among the New Caledonian members of the subgenus Trichoglene: the spinifera-group, with abdominal segment IX subquadrate; the caledoniensis-group, with venter of abdominal segment IX in ventral view produced anteriorly, proximally either rounded or tapered and somewhat triangular; and the insularis-group, with Y-shaped inferior appendages (Wells \& Johanson 2015).

In this study, three new Oxyethira (Trichoglene) species are described, two belonging to the caledoniensis-group (O. spiralis sp. nov. and O. hamus sp. nov.) and one belonging to the spiniferagroup (O. rectangulata sp. nov.).

\section{Material and methods}

The material was collected using Malaise traps (Gressit \& Gressit 1952) and preserved in $80 \%$ ethanol. For examination of the male genital structures, the abdomen was removed and cleared in $10 \% \mathrm{KOH}$ and mounted temporarily in glycerin or glycerin jelly on a slide for viewing and drawing. Pencil sketches were made using a drawing tube mounted on a Leitz Laborlux S light microscope, and then scanned and used as templates to produce vector graphics in Adobe Illustrator ver. CS6. The removed abdomens were then stored permanently with the rest of their respective bodies in microvials with $80 \%$ ethanol. The terminology used in the descriptions follows that of Kelley (1984).

\section{Institutional abbreviations}

MNHN = Muséum national d'histoire naturelle, Paris, France

NHRS $=$ Swedish Museum of Natural History, Stockholm, Sweden

\footnotetext{
$\mathrm{bp}=$ bilobed process

ej = ejaculatory duct

ia $=$ inferior appendages

sg $=$ subgenital processes

VIII $=$ segment VIII

IX $=$ segment IX
}

Abbreviations of genital structures 


\title{
Results
}

\author{
Class Insecta Linnaeus, 1758 \\ Order Trichoptera Kirby, 1813 \\ Family Hydroptilidae Stephens, 1836 \\ Genus Oxyethira Eaton, 1873 \\ Oxyethira (Trichoglene) hamus sp. nov. \\ urn:1sid:zoobank.org:act:200E6D45-51B4-4012-A3B1-4FE519ED65F6
}

Fig. $1 \mathrm{~A}-\mathrm{D}$

\section{Diagnosis}

This new species belongs to the group of Oxyethira caledoniensis. It is similar to O. houailou Wells \& Johanson, 2015 by the presence of strong sclerotized margins of the inferior appendages, each one bearing one seta in the mesal region as seen in ventral view; and by the general shape of the phallus apex, with a subdistal spine curved to the left in dorsal view. Oxyethira (Trichoglene) hamus sp. nov. is recognized by the hook-shaped apex of the long inferior appendages in lateral view (short and with pointed apex in $O$. houailou) and by the posterior margin of segment IX having a trilobed appearance in ventral view (forming a subtriangular projection in $O$. houailou).

\section{Etymology}

'Hamus', 'hook' in Latin, refers to the shape of the inferior appendages in lateral view.

\section{Material examined}

\section{Holotype}

NEW CALEDONIA - §̧; Province Sud Haute Yaté fauna reserve, $1760 \mathrm{~m} \mathrm{~S}$ of bridge Pont Perignon, $50 \mathrm{~m}$ upstream from bridge over stream; $22.14954^{\circ} \mathrm{S}, 166.701211^{\circ} \mathrm{E}$; alt. $180 \mathrm{~m}$; 14 Dec. 2003-13 Jan. 2004; K.A. Johanson leg.; Loc\#081; Malaise trap; MNHN.

\section{Paratypes}

$9 \AA \hat{\jmath}$; same collection data as for holotype; NHRS.

\section{Description}

Body. Male antennae with 18 flagellomeres. Forewing length 1.4-1.8 mm $(\mathrm{n}=10$, mean $1.5 \mathrm{~mm})$; tibial spurs $0,3,4$; forewings with venation typical for subgenus. Abdominal sternite VII without mesoventral process.

Male genitalia (Fig. 1A-D). Abdominal segment VIII almost cylindrical, with shallow incision at posterior margin in ventral view (Fig. 1C). Abdominal segment IX inserted within segment VIII; anterior margin forming three lobes in ventral view (Fig. 1C), surpassing anterior margin of segment VIII (Fig. 1A-B). Segment X not visible. Subgenital processes slightly curvilinear in dorsal view (Fig. 1B), each with pointed apex curved downward in lateral view and one bilobed process at base (Fig. 1A). Inferior appendages fused, with strongly sclerotized margins, bearing one pair of small mesal setae at posterior margin visible in dorsal (Fig. 1B) and ventral views (Fig. 1C), and one pair of small setae at inner margin visible in dorsal view (Fig. 1B); posterior margin slightly concave; in lateral view hook-shaped with apex curved backward and touching base of subgenital process (Fig. 1A). Setal lobes absent. Aedeagus elongate; in subdistal region, slender spine pointing left in dorsal view. Titillator absent (Fig. 1D). 

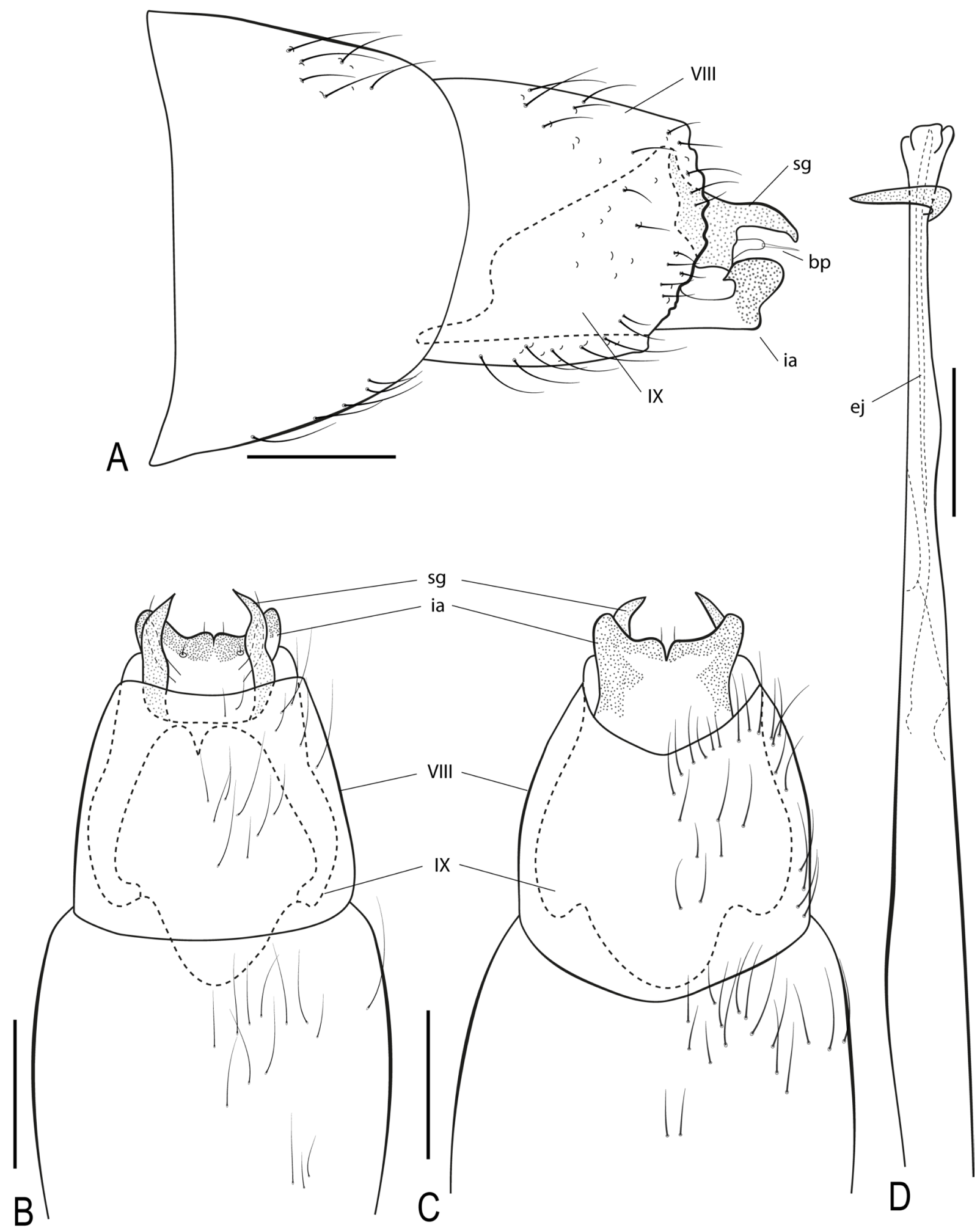

Fig. 1. Oxyethira (Trichoglene) hamus sp. nov., male genitalia. A. Lateral. B. Dorsal. C. Ventral. D. Aedeagus, dorsal. Abbreviations: See Material and methods. Scale bars $=0.1 \mathrm{~mm}$. 


\section{Oxyethira (Trichoglene) rectangulata sp. nov. urn:lsid:zoobank.org:act:C930EB33-5E37-49C2-8A94-882E97EAF988}

Fig. 2A-D

\section{Diagnosis}

Oxyethira (Trichoglene) rectangulata sp. nov. belongs to the group of Oxyethira spinifera. It is similar to $O$. tiwaka Wells \& Johanson, 2015 by the quadrangular shape of segment IX in ventral view, and in lateral view by the inferior appendages being divided into a dorsal part forming a hump and a ventral part forming a pointed projection. This species can be recognized by the rectangular shape of the inferior appendages in dorsal and ventral views, which are totally fused, bearing two pairs of small setae on the inner face (in $O$. tiwaka these appendages are much smaller and the ventral part forms a quadrate-shaped sclerotized projection in ventral view); by the shape of the subgenital process in lateral view, which is thinner and almost straight in $O$. rectangulata sp. nov., and thicker, C-shaped in $O$. tiwaka.

\section{Etymology}

'Rectangulata', from Latin, 'rectangular', refers to the shape of the inferior appendages in dorsal and ventral view.

\section{Material examined}

\section{Holotype}

NEW CALEDONIA - \; Province Sud, Haute Yaté fauna reserve, $1760 \mathrm{~m} \mathrm{~S}$ of bridge Pont Perignon, $50 \mathrm{~m}$ upstream from bridge over stream; $22.14954^{\circ} \mathrm{S}, 166.701211^{\circ} \mathrm{E}$; alt. $180 \mathrm{~m}$; 14 Dec. 2003-13 Jan. 2004; K.A. Johanson leg.; Loc\#081; Malaise trap; MNHN.

\section{Paratypes}

$2 \widehat{\partial}$; same collection data as for holotype; NHRS.

\section{Description}

Body. Male antennae with 20 flagellomeres. Forewing length 1.7-1.8 mm $(\mathrm{n}=3)$; tibial spurs $0,3,4$; forewings with venation typical for subgenus. Abdominal sternite VII with a small, pointed mesoventral process.

Male Genitalia (Fig. 2A-D). Abdominal segment VIII cylindrical with wide, V-shaped incision in ventral view (Fig. 2C). Abdominal segment IX inserted within segment VIII; anterior margin slightly concave, not surpassing anterior margin of segment VIII (Fig. 2B-C). Segment X not visible. Subgenital processes almost straight in dorsal (Fig. 2B) and ventral views (Fig. 2C), each bearing one bilobed process at base. Inferior appendages fused, rectangular in dorsal (Fig. 2B) and ventral views (Fig. 2C), bearing two pairs of small mesal setae at inner margin visible in dorsal view (Fig. 2B); divided into two parts in lateral view (Fig. 2A): dorsal part forming a truncate hump, ventral part forming pointed projection. Setal lobes absent. Aedeagus elongate, with slender apical spine curved left in dorsal view. Ejaculatory duct extending freely at apex. Titillator absent (Fig. 2D). 

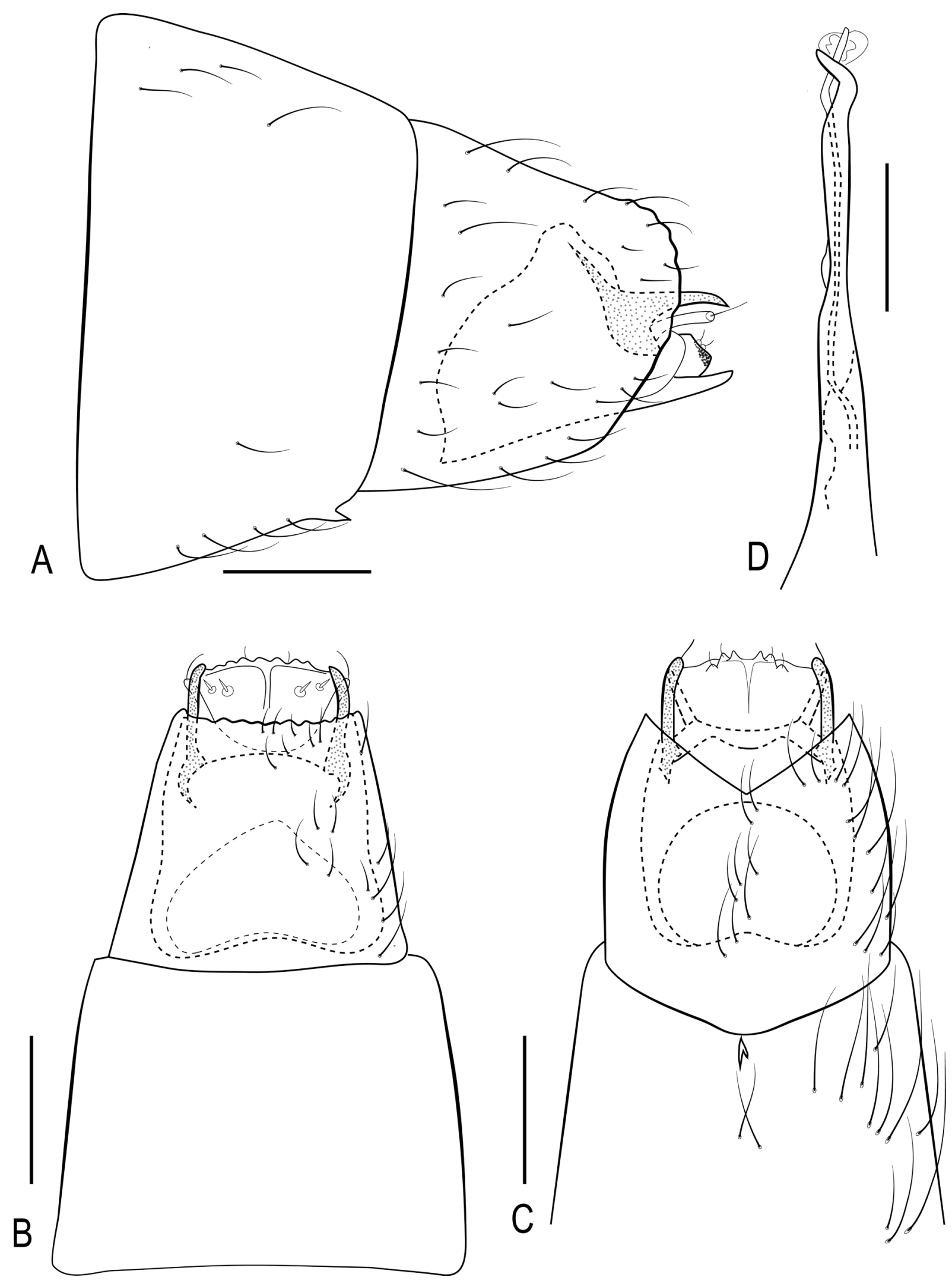

Fig. 2. Oxyethira (Trichoglene) rectangulata sp. nov., male genitalia. A. Lateral. B. Dorsal. C. Ventral. D. Aedeagus, dorsal. Scale bars $=0.1 \mathrm{~mm}$. 


\section{Oxyethira (Trichoglene) spiralis sp. nov. urn:1sid:zoobank.org:act:5027693E-FC66-4256-B619-34C77CA3E6FF}

Fig. 3A-D

\section{Diagnosis}

Based on general similarities, Oxyethira (Trichoglene) spiralis sp. nov. is tentatively placed in the group of Oxyethira caledoniensis. It is similar to O. caledoniensis Kelley, 1989 by the shape of segment IX in ventral and lateral views, with the anterior margin only slightly produced anteriorly and by the shape of the apparently fused inferior appendages. In O. caledoniensis the inferior appendages are widely separated and form bilobed sclerotized structures that are absent in $O$. spiralis sp. nov. The new species can be recognized in lateral view by the subquadrate shape of the inferior appendages, by the strongly curvilinear shape of the subgenital process in dorsal and lateral views, and by the long process spiralling around the ejaculatory duct at the phallus apex.

\section{Etymology}

'Spiralis', from Latin, 'spiral', referring to the shape of the long process present around the ejaculatory duct in this species.

\section{Material examined}

\section{Holotype}

NEW CALEDONIA • đ; Province Nord, Western slope of Kugüö Mt, Xwé Wida Di Stream, 2 km E of Koh; $21^{\circ} 35.474^{\prime}$ S, $165^{\circ} 50.776^{\prime}$ E; alt. 154 m; 20 Nov.-12 Dec. 2003; K.A. Johanson leg.; Loc\#036; Malaise trap; MNHN.

\section{Description}

Body. Male antennae with 22 flagellomeres. Forewing length $1.7 \mathrm{~mm}(\mathrm{n}=1)$; tibial spurs $0,2,4$; forewings with venation typical for subgenus. Abdominal sternite VII with a small, pointed mesoventral process.

Male genitalia (Fig. 3A-D). Abdominal segment VIII cylindrical without excisions. Abdominal segment IX inserted in segment VIII; anterior margin slightly produced anteriorly (Fig. 3A-B). Segment X not visible. Subgenital processes with strongly sigmoid shape in dorsal (Fig. 3B) and ventral views (Fig. 3C), each bearing one bilobed process at base. Inferior appendages fused and almost quadrate in lateral view (Fig. 3A). Setal lobes absent. Aedeagus elongate, long process spiralling around ejaculatory duct; ejaculatory duct extending freely in middle of two weakly sclerotized projections at phallus apex. Titillator absent (Fig. 3D).

\section{Discussion}

Despite the great morphological variation present in the genitalia of Oxyethira, all species described here present characteristics unique for the subgenus Trichoglene (Kelley 1984): segment VIII without modification; and widely separated subgenital processes that are partially fused with the pleural region of segment IX.

There are different distribution patterns for Oxyethira species in New Caledonia ranging from wide to localised, or even disjunct (north-south extremes) (Wells \& Johanson 2015). Oxyethira (Trichoglene) hamus sp. nov. and $O$. (Trichoglene) rectangulata sp. nov have their distribution restricted to the type locality in the southern region of New Caledonia (Province Sud). Other species previously described have a similar distribution pattern on the island: Oxyethira (Trichoglene) amieu Wells \& Johanson, 2015, O. (Trichoglene) insularis Kelley, 1989, O. (Trichoglene) parinsularis Wells \& Johanson, 2015 
and $O$. (Trichoglene) perignonica Wells \& Johanson, 2015. These species can be well localized or widely distributed in the Sud Province but are never found in the northern region (Province Nord) (Wells \& Johanson 2015). Oxyethira (Trichoglene) spiralis sp. nov is only known from its type locality in the Province Nord.

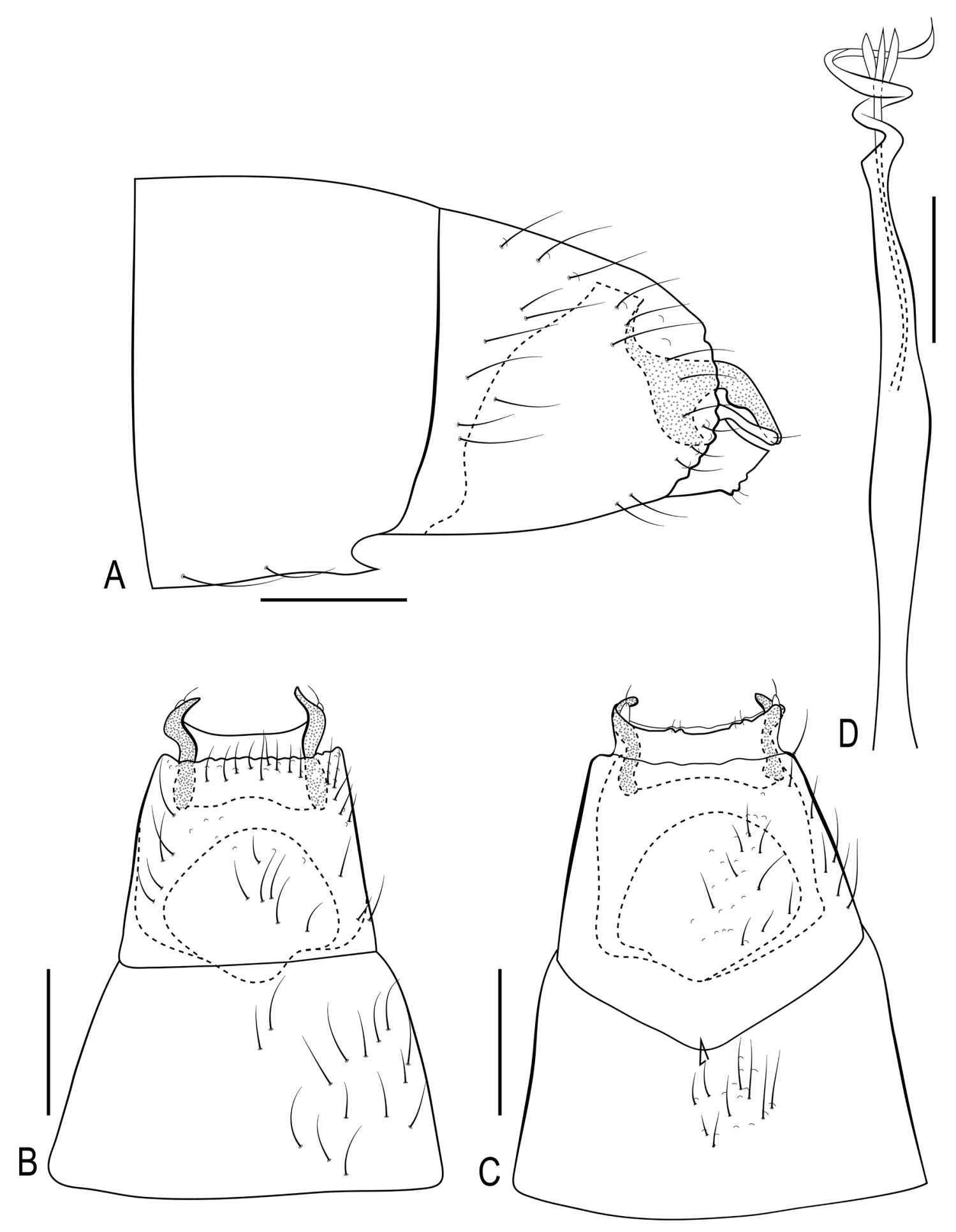

Fig. 3. Oxyethira (Trichoglene) spiralis sp. nov., male genitalia. A. Lateral. B. Dorsal. C. Ventral. D. Aedeagus, dorsal. Scale bars $=0.1 \mathrm{~mm}$. 
Wells \& Johanson (2015) reviewed the New Caledanian Oxyethira species and described 17 new species, bringing the total number of species for the island to 26. Of these, 11 species belong to Trichoglene. Together with the herein described species the diversity of Oxyethira on New Caledonia is increased by about $10 \%$, and of those in Trichoglene by almost $30 \%$.

The three new species were found among several thousand New Caledonian Hydroptilidae stored in ethanol and collected at the end of 2003 and beginning of 2004. This means that new species can still be found in material from well-studied areas that have given rise to descriptions of dozens of new species in the family Hydroptilidae (Wells \& Johanson 2012, 2014, 2015; Wells, Johanson \& Mary-Sasal 2013). This shows the potential for finding new Hydroptilidae in New Caledonia and that undescribed species are still available in collections or likely not yet collected.

\section{Acknowledgments}

This work was possible thanks to the sandwich doctoral scholarship provided by CAPES (Coordenação de Aperfeiçoamento de Pessoal de Nível Superior (Process n. 88887.508066/2020-00)) and the scholarship provided by CNPQ (Conselho Nacional de Desenvolvimento Científico e Tecnológico (Process n. 141121/2018-1)), to which we are highly grateful.

\section{References}

Gressit J.L. \& Gressit M.K. 1952. An improved Malaise Trap. Pacific Insects 4: 87-90.

Holzenthal R.W. \& Calor A.R. 2017. Catalog of the Neotropical Trichoptera (caddisflies). Zookeys 654: 1-566. https://doi.org/10.3897/zookeys.654.9516

Johanson K.A. 2011. The ecnomid caddisflies: generic composition and a male-based generic key, with description of Caledomina noumea n. g. et n. sp. from New Caledonia (Trichoptera: Ecnomidae). Annales de la Société Entomologique de France (Nouvelle série) 47: 344-349. https://doi.org/10.1080/00379271.2011.10697726

Johanson K.A. \& Wells A. 2019. New Caledonia's Trichoptera - present status of knowledge. Zoosymposia 14: 87-102. https://doi.org/10.11646/zoosymposia.14.1.12

Kelley R.W. 1984. Phylogeny, morphology and classification of the micro-caddisfly genus Oxyethira Eaton (Trichoptera: Hydroptilidae). Transactions of the American Entomological Society 110: 435-463.

Kelley R.W. 1989. New species of micro-caddisflies (Trichoptera: Hydroptilidae) from New Caledonia, Vanuatu and Fiji. Proceedings of the Entomological Society of Washington 91 (2): 190-202.

Morse J.C. 2021. Trichoptera World Checklist. Available from http://entweb.sites.clemson.edu/database/trichopt/index.htm [accessed 15 Oct. 2021].

Özdikmen H. 2007. A nomenclatural act: replacement names for two homonymous caddisfly generic names (Trichoptera). Munis Entomology \& Zoology 2 (2): 443-444.

Wells A. \& Johanson K.A. 2012. Review of the New Caledonian species of Paroxyethira Mosely, 1924 (Trichoptera: Hydroptilidae). Zootaxa 3478 (1): 330-344. https://doi.org/10.11646/zootaxa.3478.1.31

Wells A. \& Johanson K.A. 2014. Review of the New Caledonian species of Acritoptila Wells, 1982 (Trichoptera, Insecta), with descriptions of 3 new species. ZooKeys 397: 1-23.

https://doi.org/10.3897/zookeys.397.7059

Wells A. \& Johanson K.A. 2015. Review of New Caledonian species of Oxyethira Eaton, with description of 17 new species, and new records for Hydroptila Dalman and Hellyethira Neboiss (Trichoptera, Hydroptilidae). ZooKeys 530: 37-90. https://doi.org/10.3897/zookeys.530.6047 
Wells A., Johanson K.A. \& Mary-Sasal N. 2013. The New Caledonian genus Caledonotrichia Sykora (Trichoptera, Insecta) reviewed, with descriptions of 6 new species. ZooKeys 287: 59-89.

https://doi.org/10.3897/zookeys.287.4615

Manuscript received: 17 September 2021

Manuscript accepted: 17 November 2021

Published on: 12 January 2022

Topic editor: Nesrine Akkari

Section editor: Helen M. Barber-James

Desk editor: Eva-Maria Levermann

Printed versions of all papers are also deposited in the libraries of the institutes that are members of the EJT consortium: Muséum national d'histoire naturelle, Paris, France; Meise Botanic Garden, Belgium; Royal Museum for Central Africa, Tervuren, Belgium; Royal Belgian Institute of Natural Sciences, Brussels, Belgium; Natural History Museum of Denmark, Copenhagen, Denmark; Naturalis Biodiversity Center, Leiden, the Netherlands; Museo Nacional de Ciencias Naturales-CSIC, Madrid, Spain; Real Jardín Botánico de Madrid CSIC, Spain; Zoological Research Museum Alexander Koenig, Bonn, Germany; National Museum, Prague, Czech Republic. 